\title{
A SOCIOCULTURAL LEARNING FRAMEWORK FOR INCLUSIVE PEDAGOGY IN ENGINEERING
}

\author{
Stephanie Farrell, ${ }^{1}$ Allison Godwin, ${ }^{2}$ And Donna M. Riley ${ }^{2}$ \\ 1. Rowan University - Glassboro, NJ 08028 \\ 2. Purdue University • West Lafayette, IN 47907
}

\section{INTRODUCTION}

$\mathrm{T}$ There is a critical need to diversify and expand the STEM workforce in the United States to remain competitive in a global economy and to serve the needs of society. Recognizing the need to attract and retain the most talented individuals to STEM professions, the National Academies declared that diversity in STEM must be a national priority. ${ }^{[1]}$ Additionally, a free and just society is one without barriers to equitable access and with full participation by all in the benefits of that society. And yet, the opportunity to pursue STEM degrees and participation is highly varied..$^{[2,3]}$ These multiple motivations provide important reasons to support diversity, equity, and inclusion (DEI) in chemical engineering education.

Lucena ${ }^{[4]}$ and Slaton ${ }^{[5]}$ trace the history of arguments making the case for diversity from social justice to national security to workforce imperatives. Research has shown that improving diversity in a workforce enhances creativity and innovation, and increases productivity and financial performance. ${ }^{[6-8]}$ In the educational environment there is compelling evidence that diversity among students and faculty is crucially important to the intellectual and social development of all students. ${ }^{[9-12]}$ It is essential to critically question the norms of "the way things are" to explicitly consider how what we do actively supports DEI. ${ }^{[13]}$

Indeed, the historic participation rates of various groups in engineering are a symptom of a system that is not equitable for all. Traditionally underrepresented racial/ethnic groups (American Indian/Alaska Native, Black, Hispanic/Latino, and Native Hawaiian/Pacific Islander; terminology used in Federal reporting) represent about $31 \%$ of the general population in the United States, yet they account for only $17.9 \%$ of undergraduate students enrolled in engineering and $14.3 \%$ of bachelor's degrees attained. ${ }^{[14]}$ Women are also underrepresented in engineering - Asian and White women account for $15.2 \%$ of undergraduate students enrolled in engineering and only $14.8 \%$ of bachelor's degrees attained. ${ }^{[14]}$ Chemical engineering trends higher than the average across engineering disciplines on representation of female degree recipients. ${ }^{[15]}$ Research shows that underrepresented students are also less likely to remain in STEM fields than their overrepresented peers. ${ }^{[14,16,17]}$ And while diversity traditionally has focused on increasing representation of historically underrepresented groups, other dimensions of diversity deserve serious attention - for example, gender identity that includes non-binary participants, socioeconomic status, religious belief, veteran status, disability, and sexual orientation. ${ }^{[18]}$ Together, we describe these identities as excluded identities, or identities that have been systematically disadvantaged. These identities are not additive, and the experiences of students at the intersections of these identities have layered experiences of exclusion. ${ }^{[19]}$ We acknowledge that there is a wide range of terms used in describing inequity with various historical meanings and impact on the communities they describe. 
Where possible, the best approach is to respect the language that people use to describe themselves; that is, describe participants as they prefer to be described. ${ }^{[20]}$

\section{Factors Contributing to a Lack of Diversity}

Diversity and inclusion on campuses are multidimensional and complex. Milem ${ }^{[10]}$ presented a framework for campus climate in which institutional context has five interconnected dimensions:

- an organizational/structural dimension represents ways in which benefits for some groups are embedded into the structural practices and policies of the institution;

- a historical legacy dimension considers how the history of exclusion shapes present dynamics at the institution;

- a psychological climate is created by individuals' views and attitudes about engaging with diversity;

- a behavioral dimension relates to the nature of interactions among diverse individuals and groups; and

- the dimension of compositional diversity refers to student enrollment and faculty/staff hiring.

Achieving and maintaining compositional diversity requires inclusion - intentional engagement with all dimensions of diversity in the framework for campus climate. ${ }^{[21]}$

\section{The Importance of Inclusion}

Failure to create an inclusive environment negatively affects all students; ${ }^{[9,11,12]}$ one of the key reasons cited for students leaving STEM is the perception of a chilly climate, especially by those with excluded identities. ${ }^{[22]}$ In addition, the culture of STEM education negatively affects students' interest, self-concept, sense of belonging, and persistence in technical disciplines. ${ }^{[23]}$ Numerous scholars have studied aspects of engineering culture that serve as barriers to inclusion in engineering education and in the profession, as summarized in Table 1. Although engineering culture varies by context and cannot be characterized as monolithic, these are common elements that overlap across different settings.

Not only are DEI linked to learning outcomes and academic achievement, they are also part of a professional skill set and ethical responsibility of engineers. An ABET student outcomes criterion specifies "an ability to function effectively on a team whose members together provide leadership, create a collaborative and inclusive environment, establish goals, plan tasks, and meet objectives" as an essential skill. ${ }^{[24]}$ In January 2021 AIChE approved a new Equity, Diversity and Inclusion statement establishing the obligation of all members to support DEI, anti-racism, and learning (IDEAL). ${ }^{[25]}$ AIChE also includes "fostering an environment of diversity, equity and inclusion" in its Code of Ethics. ${ }^{[26]}$ As educators, we need to ensure that our students develop knowledge, skills and behaviors to support DEI as they progress through their engineering program.

\section{Purpose}

Beginning January 1, 2021, Chemical Engineering Education (CEE) requires all submissions to consider all submissions through a lens of DEI in alignment with other scholarly aspects of the work. This paper describes a framework for classroom inclusion based on research in three interconnected areas: learner identity, classroom context, and engineering culture. The authors hope that this paper will serve as a resource for $C E E$ authors to incorporate inclusive pedagogy into the design and implementation of their chemical engineering education efforts.

\section{Sociocultural Learning Framework}

We frame this work in a sociocultural learning framework. This framework emphasizes that a learner's environment and larger context are inextricably linked with their learning development and that individuals learn through collaborative dialogues with peers. ${ }^{[50]}$ Students bring their prior backgrounds, knowledge, experiences, attitudes, and beliefs into engineering classrooms. In turn, they interact with peers and instructors within the classroom. Classrooms are situated in a larger cultural context of higher education, engineering, and society at large. All of these layers inform how students engage with DEI and provide various levels at which key issues in both pedagogy and research can be addressed. Figure 1 represents the conceptual situation of these sociocultural elements.

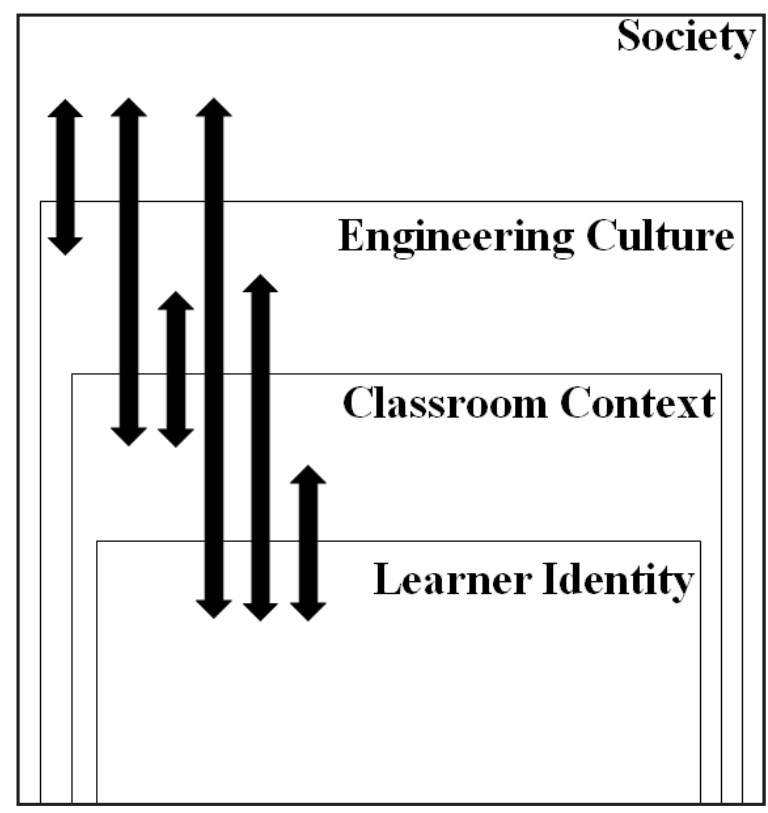

Figure 1. Sociocultural perspective of how context informs a learner's experiences. 
Table 1

Aspects of engineering culture that serve as barriers to inclusion and participation

Elitism - Scholars have identified numerous ways in which elitism is manifested in engineering culture. A few examples are provided here:

The Banking Model of Education - Paolo Freire's banking model of education is a metaphor that describes students as empty containers into which knowledge is deposited by teachers. ${ }^{[27]}$ The model positions teachers as experts who narrate facts, and students as obedient, passive learners who repeat those facts. Some of the effects of this "sage on the stage" style of teaching are that students' prior knowledge is devalued, students do not learn to think critically, and hierarchical values and culture are reproduced. A large observational study of STEM classrooms showed that instructors rely predominantly on lecture, despite the ineffectiveness of this teaching style. ${ }^{[28]}$

Epistemological Dominance - Deeply ingrained in STEM culture are beliefs regarding the nature of knowledge and process of knowing. STEM epistemology values universal truths and "knowing that" over "knowing how," and devalues other ways of knowing. ${ }^{[23]}$ This elitism can disadvantage nontraditional and underrepresented students as well as their communities. ${ }^{[29,30]}$

Majorism - Another type of superiority termed "majorism" by Carrigan and Bardini is the preferential treatment of STEM over liberal arts. ${ }^{[31]}$ The fusion of neoliberal ideology and epistemic bias against humanistic inquiry works against educational goals of critical thinking and social responsibility.

Technical Social Dualism - An ideological distinction between "technical" and "social" engineering subfields and work activities, resulting in a common perception that experiences of marginalized identity groups (especially women and LGBTQ+) are "social" or "political" and therefore not relevant to technical work. ${ }^{[32,33]}$ An extension of this is that work related to DEI is devalued and not considered part of "real engineering work."

Depoliticization - An ideology that promotes engineering as a purely "technical" space where "social" or "political" issues such as inequality are tangential (at best) or irrelevant to engineers' work. ${ }^{[33]}$ This ideology is supported by traditional engineering pedagogy and curriculum. ${ }^{[34]}$

Meritocratic Ideology - The belief that inequalities are the result of a well-functioning social system that rewards talent and hard work. Researchers have shown that meritocratic ideals legitimize social injustices and serve as a barrier to equality. ${ }^{[33,35]}$

Hidden \& Null Curriculum - The unofficial, implicit messages that students receive about disciplinary perceptions, values, and expectations. Villanueva et al. ${ }^{[36]}$ uncover themes related to a perceived lack of work-life balance and elitism in engineering. Bejerano and Bartosh ${ }^{[37]}$ reveal hidden norms of masculinity that perpetuate gendered divisions in the discipline. Null curriculum refers to what is not taught in the curriculum. What educators teach through the null curriculum makes us complicit in the status quo, including racial and gender inequality in the profession. ${ }^{[38]}$

Whiteness/Masculinity/Heteronormativity - Numerous scholars have unpacked how the history and norms of engineering have perpetuated and valued whiteness, ${ }^{[39-43]}$ masculinity, ${ }^{[39,43-45]}$ and heteronormativity ${ }^{[33]}$ in STEM fields in higher education, and the ways in which these norms serve as barriers to students from non-dominant groups.

Stereotype Threat - The concern of confirming a negative stereotype about one's identity group and can elicit a psychological threat that undermines performance and aspirations in that domain. Several studies have explored the manifestations of stereotype threat, and it influences performance and persistence of women and Black, Indigenous, and Latinx students in STEM. ${ }^{[46-49]}$ 


\section{STRATEGIES}

In this section we discuss individual strategies to address and incorporate DEI into chemical engineering education. Our discussions focus on the locus of individual control-on learner identity and classroom context - and are informed by the literature on a larger engineering culture. This section is not an exhaustive presentation of the research-based ways to consider DEI, nor are the strategies intended to be prescriptive; we instead provide suggestions as a starting point for engineering faculty who wish to integrate DEI into their teaching and/or scholarship. Instructors should consider whether strategies are appropriate for their context (e.g. student demographics and institutional support for DEI). We also encourage instructors to monitor their own attitudes, assumptions, and practices through guided reflection to create an inclusive classroom environment. Barker ${ }^{[51]}$ provides a useful checklist for guided self-reflection.

\section{Supporting the Development of Learner Identity}

Understand Your Students. Identity is an enduring and continuous sense of who one is ${ }^{[52]}$ and consists of multiple and overlapping aspects of oneself. ${ }^{[53]}$ For example, a student might identify as a chemical engineer, a Black woman, and a musician. As students engage in an engineering context, they constantly negotiate what it means to be a chemical engineer; if that role is aligned with their identity; how the norms, values, expectations, and climate of engineering support or do not support seeing themselves as the kind of person who can do chemical engineering; and, ultimately, if they belong. Koretsky et al. ${ }^{[54]}$ implemented pedagogical reform to introduce inclusive practices that support the connections between chemical engineering identity, personal identities, and professional competencies.

The default for students with excluded identities in engineering is identity threat or the negative experience in situations where one's social group is underrepresented, devalued, or stereotyped to be inferior. ${ }^{[47,55-57]}$ The history and norms of engineering culture (see Table 1) and the usual experience of being one of a small number in an engineering classroom create a space in which students with excluded identities constantly grapple with questions about if they belong. Often instructors believe that a lack of bias or equal treatment for all students (an identity-evasive approach) creates inclusive classrooms; however, only an active approach to creating identity-safe peer and instructor interactions, a classroom context that values diverse identities, and an inclusive engineering culture can create ways in which students can feel like they matter and that they belong. ${ }^{[58]}$

Power relations are socially constructed, and often instructors are positioned as the knowledgeable authority in the classroom. ${ }^{[27,59]}$ Often instructors are presented as representa- tives of success and potential gatekeepers to advancement in a discipline. As such, instructors can have substantial power over students' beliefs about their ability to succeed, interest in the subject, and feelings of recognition as an engineer. ${ }^{[60,61]}$ Instructors can begin to create inclusive classrooms by sharing power with students and creating opportunities for students to shape what happens in the classroom. ${ }^{[62,63]}$

Even small cues can create identity-safe and supporting classrooms. Language used can convey messages about who is valued and belongs. Addressing students in inclusive terms like "y'all," "folks," and "everyone," instead of gendered terms like "you guys" can shift the default of a masculine engineering stereotype. ${ }^{[64]}$ Similarly, using "first-year" rather than "freshman" also shifts language to gender-inclusive terms. Using correct pronouns and names-in-use ${ }^{1}$ also engages these simple cues that convey students belong. These small changes are more than political correctness or semantics; they shape students' experiences within the classroom and communicate everyday messages about who belongs. ${ }^{[65]}$ These efforts should go beyond an individual instructor's effort in their classroom to consistent norms within departments and universities.

Recognition by oneself and by important others like peers and instructors as the kind of person who can do engineering has a significant impact on students' developing identities. ${ }^{[66]}$ Instructors can intentionally create opportunities for recognition by having high expectations but also providing the necessary support to achieve those high expectations; devoting resources of attention and opportunities to ask questions outside of normal class hours; creating a studentcentered rather than instructor-centered environment (see McCombs and Whisler ${ }^{[66]}$ and Wright ${ }^{[67]}$ for more details); and explicitly affirming students' contributions and capabilities. ${ }^{[68}$ Peers also play an important role in identity-affirming experiences. Students feel recognized when they are able to share their interest in and excitement for their discipline and when peers demonstrate trust in intelligence and abilities. ${ }^{[69]}$ Collaborative work can support these interactions, but these must also be carefully managed to support positive and inclusive interactions.$^{[70]}$ Attending to intercultural dynamics among students and between students and instructors can improve psychological safety in teams, as well as team effectiveness and innovation. ${ }^{[71]}$ Ladson-Billings ${ }^{[72]}$ presents a framework for culturally relevant pedagogy based on the practices and reflections of exemplary teachers of African-American students. Reed ${ }^{[73]}$ provides recommendations on developing inclusive cultures in transnational settings. Butterfield et al. ${ }^{\left[{ }^{[7]}\right.}$ suggest strategies for creating inclusive classrooms for LGBTQ+ students.

1. A name-in-use or chosen name is the use of a name, usually a firs name, that is different from a person's legal name. There are many reasons why someone may not use their legal name. While the most visible may be to reflect their gender identity, other reasons include using an Americanized name, or simply distinguishing oneself from someone with a similar name. 
Representation Matters. When students can see people like them who are represented in the curriculum and in the engineering community, they are more likely to be interested and engaged with the subject, have a higher sense of belonging, and are more likely to do well and remain within the field of study. ${ }^{[75-77]}$ Instructors can highlight contributions and perspectives from a diverse range of scholars in the curriculum. Adopting a multicultural ideology, which recognizes and celebrates group differences, can shift the default of a White, male engineering stereotype.

Following on hooks ${ }^{\text {' }}{ }^{[59]}$ call to decenter whiteness, masculinity, and Western knowledge, the contexts and applications for engineering thermodynamics were expanded to address, for example, energy innovation in different national contexts; the relationship among gender, energy, and economic development; climate justice; and highlighting contributions of women of color in thermodynamics. ${ }^{[78-81]}$ These topics can be readily incorporated as individual problems, reflective exercises, case studies, or short modules, enhancing the approachability of the material and supporting student learning. Mejia and de Paula ${ }^{[82]}$ illuminate indigenous engineering contributions to Western society and argue the importance of integrating examples of indigenous engineering practices into traditional engineering classrooms.

Asset-Based Approaches. Much of the research on students with excluded identities approaches diversity from a deficit model that focuses on what these students lack. ${ }^{[29]}$ While academic support structures are important, we must embrace an asset-based model of diversity that values the unique strengths that students bring to engineering in order to unlock their potential.

Funds of knowledge are the skills and knowledge that students bring from their family, cultural, and work backgrounds, which can be crucial to engineering innovation but are often neglected in the classroom or curriculum. Traditional engineering culture and curricula value theory ("knowing that") over practical experience ("knowing how"). ${ }^{[83]}$ Nontraditional students often possess practical skills that could be viewed as an asset, yet they feel that their skills and experiences are undervalued in engineering classrooms. For example, Svihla et al ${ }^{[84]}$ compare the problem-framing skills of firstyear engineering students from traditional backgrounds versus low-income first-generation college students from rural backgrounds. The first-generation college students had lower confidence in their engineering ability, yet demonstrated better problem-framing skills. Gomez and Svihla ${ }^{[85]}$ develop community-inspired design challenges as asset-based activities that draw on the strengths and knowledge of rural students. Rolston and Cox ${ }^{[29]}$ explore the historical context of the "mental/manual divide" in engineering education and present Engineering by Doing (EbD) as a pedagogy that makes backgrounds of nontraditional students visible and valued in the curriculum. Smith and Lucena ${ }^{[86]}$ show that low-income and first-generation college students draw on funds of knowledge acquired growing up in poor families, and validation of these funds of knowledge can help establish a sense of belonging in engineering.

Supporting the Whole Student. Student wellness has become an increasing topic of importance in higher education as the rise of mental health issues is becoming increasingly prominent. ${ }^{[87]}$ Engineering culture, in particular, has been described as a culture of "suffering and shared hardship" [88] and "a meritocracy of difficulty." "[89] More recent work has documented differential impacts of a "stress culture" on students from excluded groups and emphasizes how this culture often manifests in students experiencing a lack of caring and community (i.e. "I find many professors' attitudes towards student work is 'get it done' or 'deal with it."').[90] This emphasis on engineering rigor rather than the whole student creates a context in which students and instructors may not give attention to wellbeing or consider how the context of a student's life outside of the four walls of the classroom affects their ability to learn and engage with engineering. Supportive faculty-student interaction can have a significant impact on the student experience. ${ }^{[91,92]}$

Research from positive psychology emphasizes that in order to do well, individuals need to feel well. ${ }^{[93]}$ There are ways that research-based interventions and cultivation of a culture of care can combat the norms of a stress culture and support the whole student. Promoting mindfulness and reflection through even a 15-minute exercise has been linked to better problem solving and innovation ${ }^{[94]}$ as well as feelings of belonging and motivation. ${ }^{[95,96]}$ A range of research indicates that communicating care can support students as well. Instructors' behaviors that communicate care beyond “just teaching" support students' academic success (refer to Chang ${ }^{[97]}$ and Chhoun and Wallace ${ }^{[98]}$, particularly for students from excluded groups). ${ }^{[99,100]}$

You do not need to be a counselor to ask if a student is okay. Simply noticing and reacting can provide needed connection and support for students. ${ }^{[101]}$ You may want to keep some tissues readily available in your office; sometimes students have no one else who has asked or noticed that they are overwhelmed, stressed, or struggling. Emotions may come up during advising or office hour interactions. The expression of empathy and care, particularly from White and male instructors, can also disrupt the norms in engineering that separate the technical content from social realities and the common expectations that female instructors and instructors of color take up a nurturing role. ${ }^{[102,103]}$ Communicating care does not mean that you need to say, "Yes," to every request. Part of supporting students is setting high expectations and providing the necessary support for all students to achieve those goals. ${ }^{[104]}$ Care can also be designed into a classroom structure from the beginning. Rather than making accommodations or granting extensions for problem sets that take hours upon 
hours each week or timed high-stakes testing, assessment and classroom activities can be intentionally crafted to meet all learners' needs. There are many lessons learned from the pivot to online learning with the COVID-19 pandemic that can support creative solutions for assessment. ${ }^{[73]}$ We discuss these considerations more in the assessment section below.

\section{Creating an Inclusive Classroom Environment}

Classroom Norms. Classroom norms are an agreement among members of a class about behavioral expectations and interpersonal interactions. What you say and do on the first day of class can signal your commitment to DEI and can help shape norms that support academic success, belonging, and the formation of a healthy professional identity that is congruent with one's authentic sense of self. ${ }^{[105]}$ The instructor can facilitate the construction of classroom norms as a community. For example, these might include encouraging the expression of different ideas and perspectives; acknowledging and considering those ideas; listening to others without interrupting; and inviting others to speak. The class community should also share responsibility for upholding the classroom norms.

Using appropriate names and pronouns is an important way of establishing norms of respect with students and colleagues. You can come prepared to respect students' names and pronouns on the first day of class. Consider sending a survey to students before the first day to ask them what name and pronouns they will use in your class. We recommend against doing a roll call on the first day using names in the university computer system (even if the university has a name-in-use policy), as name and pronoun use can vary by context. Do not forget to let students know the name they should use to address you and what pronouns you use. Additional resources on name and pronoun use are the Anti-Defamation League's Using Correct Names and Pronouns ${ }^{[106]}$ and Magna Publications' Supporting Transgender Students in the Classroom. ${ }^{[107]}$

A diversity and inclusion statement on your syllabus explains your personal commitment to creating an inclusive environment for students. This statement is different from a standard nondiscrimination statement that is required or recommended at many institutions. The diversity and inclusion statement should be your own, but some important elements that you may wish to include are (1) a description of why is inclusion important; (2) that everyone's contributions are valued in your class; (3) that identity matters and that you welcome all students; (4) your expectations for inclusive, welcoming, and respectful behavior; and (5) opening the door for suggestions and improvement. Example inclusion statements can be found online; one particularly useful collection of examples is curated by Clemson University. ${ }^{[108]}$ The diversity and inclusion statement is an opportunity to send a first message about professionalizing DEI as a skill set and ethical responsibility - a message that should be modeled and reinforced throughout the semester.

Vol. 55, No. 4, Fall 2021
The physical setup of chairs, tables, and presentation in a classroom can significantly influence learning. Instructional communication theory suggests that seating arrangements can affect how the instructor communicates with students and how the students interact with one another, thus impacting engagement, motivation, and focus ${ }^{[109]}$ Consider a traditional lecture setup with rows of fixed seating, where students face the instructor and have their backs to one another. This classroom orientation minimizes communication between students, and it encourages a "sage-on-the-stage" learning environment. If there is interaction between the student and the professor, it is likely to involve the students in the first row or through the center of the classroom. Any type of furniture rearrangement that arranges students in smaller groups facing each other supports better interaction between students and helps to create a community where students work together and are more actively engaged in the learning process. Even if the furniture is fixed, you can increase student interaction through working in pairs or other arrangements to the extent possible.

In addition to these practices, instructors can apply universal design principles to ensure that their class can be accessed and understood to the greatest extent by all students. Students with documented disabilities may request learning accommodations; however, only a small fraction of students with disabilities actually request accommodations due to apprehension about disclosure of a disability because of perceived stigmatization. ${ }^{[110,111]}$ Instead of requiring students to document their disabilities and request accommodations, universal design addresses diverse learning needs from the onset of planning instruction, environment, and assessment by recognizing that students have varying individual needs and preferences. The Universal Design for Learning (UDL) framework is grounded in cognitive neuroscience and is based on three basic principles: multiple means of engagement, multiple means of representation, and multiple means of expression. ${ }^{[12]}$ A few examples of UDL strategies are:

- Remove barriers such as lack of clarity by making learning objectives explicit and aligning learning objectives with content and assessment.

- Provide options and flexibility for students to demonstrate what they have learned. Offer assignment and assessment options as appropriate for the learning objectives (essay, video, podcast, etc.)

- Provide flexible and comfortable work spaces (collaboration space for group work, quiet space for individual work; allow noise cancellation earbuds).

- Provide prompt, regular, formative feedback.

- Use assistive technology to remove barriers to content by including closed captioning, and ensuring the course materials are accessible for screen readers. 
A resource for universal design in teaching and learning is the University of Washington's Center for Universal Design in Education. ${ }^{[113]}$

Making Learning Processes and Academic Culture Transparent. When using pedagogies that differ in large or small ways from the norms to which students are accustomed, it is important to make goals and methods as transparent as possible. This transparency provides several benefits, including inviting students to be reflective and self-directed learners, ${ }^{[114]}$ involving students as co-learners, and demystifying teaching and learning processes for students. ${ }^{[15]}$ It can be helpful to set explicit goals and expectations around inclusive classrooms and to explain how particular choices of course content, learning activities, and assignments achieve those goals. Having explained those goals, it can be empowering for students to play a role in selecting topics, problems, or other aspects of the work you will do together.

Thinking with students about the purpose of higher education and their personal motivations for pursuing their education can help broaden and strengthen their motivation and help make the case for particular classroom choices around teaching and learning. For example, is the goal to build intellectual power in order to think critically and act reflectively in the world? Or are they seeking knowledge for a specific topic or to pursue a specific career or credential? Are students there to meet parental expectations? Is their motivation something they have considered before? Do they even view it as a choice? In this context, why is an inclusive classroom important to you, and to other students? Why would inclusion matter for students coming with different types of motivations? Instructors navigating this type of conversation the first time may feel apprehensive because the conversation can go in many directions and instructors may not be fully prepared for the variety of diversity, equity, and inclusion considerations that may arise. It is important for instructors to meet students where they are and to approach the conversation with humility and transparency. Instructors can bring a willingness to learn and revisit something if needed.

Similarly, instructors can lay out an explicit roadmap for students with diverse backgrounds and experience to navigate their learning. Students have different perceptions and understandings about how college works. For example, knowing that internships might be available, as well as how and when to pursue them, is not widely known to all students. ${ }^{[40]}$ Students may not recognize that a syllabus, or a textbook's table of contents, represents a set of choices made by its author, and could be otherwise. When presenting a syllabus for the first time, ask students to critique it - this both guarantees they read it and opens up the possibility to make some changes or to clarify goals and expectations. Such an exercise reveals power relationships and dynamics in the classroom, offering a chance to discuss them and shift them to a degree. ${ }^{[27]}$
Research on growth mindset shows that when individuals understand that their intellect is malleable, they are more likely to embrace challenging problems and more likely to work through them. ${ }^{[16]}$ Growth mindset is the belief that you can cultivate and expand your abilities, as opposed to the belief that ability is innate. While research on growth mindset in STEM higher education contexts is scant, Yaeger et al. ${ }^{[117]}$ show that a short growth mindset intervention improved grades among lower-achieving students and increased overall enrollment to advanced mathematics courses in secondary education in the United States. Importantly, the study links sustained effects of the growth mindset intervention to contexts in which peer norms aligned with the messages of the intervention. Educators can promote a growth mindset through consistent messaging; through activities that give students time and space to tackle complex, challenging problems; and by creating an environment in which it is safe to fail, helping students reflect on and learn from mistakes.

Making it okay to be wrong in a classroom can make learning transparent and create a more inclusive learning environment at the same time. It takes a certain amount of vulnerability from the faculty member to model this behavior, but often more can be learned from an error than a perfectly executed example. Once students understand that errors are opportunities for learning, they too may be willing to be more vulnerable with one another and support classmates through the learning process. Understanding that intelligence is not fixed is key to this willingness to be vulnerable and the attendant growth opportunities. ${ }^{[112]}$ Moreover, a faculty member's beliefs around malleability of ability in students is linked to greater student motivation and more equitable learning outcomes. ${ }^{[118]}$

In all of these approaches, attending to the hidden curriculum (the tacit lessons and cues students pick up from classroom interactions and activities) can communicate inclusion in powerful ways. Making students aware of the hidden curriculum - giving them the ability to recognize and reflect upon it - can be a powerful tool to generate mindfulness around inclusion and to enlist students' help in creating a more inclusive classroom.

Use Socially Relevant Examples. It is well established that students with excluded identities in engineering are drawn in greater proportions to fields in which there is a strong connection between engineering and "doing good." Framing engineering in an ethic of care can promote girls' participation in engineering and a conception of engineering that aligns with their notion of becoming caring professionals. ${ }^{[119]}$ Prosocial interests are a significant factor in motivating women students to leave engineering to pursue other fields. ${ }^{[120]}$ The desire to help others, or an equity ethic, has been shown to be an important aspect of career aspirations of Black and Latinx students. Many Black, Indigenous, 
and Latinx as well as nontraditional students are drawn to projects that have a societal benefit or social justice element. [121] Integrating topics of equity and social justice into the engineering curriculum helps to frame engineering as a caring profession and presents broader career possibilities that align with students' interests, values, and professional aspirations.

A variety of resources are available to support curriculum change and content development. Gendered Innovation's curated case studies illustrate how sex, gender, and intersectional analysis lead to innovation. ${ }^{[122]}$ Riley ${ }^{[123]}$ provides a roadmap for engineers to engage in learning and action for social justice and peace, along with a collection of case studies that inspire change. Johnson et al. ${ }^{[124]}$ describe the integration of topics of social justice into a course on control systems engineering. Karwat ${ }^{[125]}$ provides examples of organizations that use engineering and technology to promote the values of peace, social justice, and environmental protection.

Involving students in the co-creation of content is an effective change strategy that engages students in the design of their learning experience. As active partners in teaching and learning, students contribute to the development of content, examples, case studies, and projects that are meaningful and relevant to them. In addition, co-creation of content offers benefits such as enhanced student-instructor and studentstudent relationships, ${ }^{[126]}$ increased student satisfaction, ${ }^{[127]}$ and improved academic performance. ${ }^{[128]}$ It can also be an effective vehicle for shifting classroom power dynamics and welcoming students as authorities. ${ }^{[59]}$

\section{ASSESSMENT}

It might be surprising that assessment is a part of considering DEI in chemical engineering education as some might think of it as an objective measure of learning, but the purpose, use, and implications of assessments should deeply consider fairness from an equity perspective (i.e. not "everyone gets the same," which is equality, but "everyone gets an equal opportunity to demonstrate what they know"). [129] The focus of this section is on assessment within a classroom, but these considerations are also important in research instruments as well. ${ }^{[130]}$ There are various considerations of fairness in assessment content, context, responses, opportunity, and use that can affect teaching and research.

In considering what goes into assessments, instructors should only assess what has been formally taught in the classroom, and what is taught should be aligned with explicit learning objectives. This approach not only creates alignment between content, assessment, and pedagogy, ${ }^{[112]}$ but also makes the hidden curriculum more explicit to students. What is assessed also communicates what is important. Considering the purpose of assessment (i.e. feedback, individual versus group, summative, etc.) and varying the types of assessment in a class can provide various ways for students to demonstrate what they know. Often, engineering education defaults to only high-stakes summative testing, but solely using this approach has documented negative impacts on students' wellbeing (e.g. test anxiety ${ }^{[131,132]}$ ) as well as priming identity threat for groups with excluded identities. The testing context can play a critical role in temporarily suppressing the intellectual performance, creating an illusion of group differences in ability. ${ }^{[133]}$ Various approaches have been suggested for mitigating this concern, including use of formative assessment, fostering a growth mindset, and providing feedback and assessment that motivate students. (Several resources provide practical recommendations for reducing stereotype threat, ${ }^{[134-136]}$ and Riley ${ }^{[79]}$ presents liberative assessment approaches for use with critical pedagogies and other studentcentered learning contexts.) Wiggins ${ }^{[137]}$ makes the case for authentic assessment that requires the use of acquired knowledge to perform effectively on worthy intellectual tasks.

The responses on assessments should be considered after implementation. Sometimes, problems or responses to questions can be solved in ways that were not intended in the instructor design. To the extent that responses are more typical of some groups than others, bias can emerge in the testing and interpretation of results. One example might be the use of a term that did not appear regularly in class, but is easily interpreted by English as first language students compared to English not as first language students. This outcome is linked to the opportunities that students have to learn about particular content and skills targeted by the test. Focusing only on content specifically described by the learning objectives and taught in class can help reduce this potential bias in assessment.

Finally, the use of assessments must also be considered, particularly in the case where the individual does not have control over the content and context of the assessment (e.g. the use of cumulative GPA as the only measure of achievement for admissions decisions or scholarships). While these measures provide quick ways to compare students, they often reinforce norms in engineering of meritocracy, whiteness, and masculinity, and can contribute directly to inequity (refer to Smith and Reeves ${ }^{[138]}$ for an example). A consideration of other factors in these decisions and a search of possible sources of bias (based on institutional data or research) can provide reassurance that bias is limited in these decisions. For a full discussion of fairness in assessment, see AERA, APA, and NCME. ${ }^{[129]}$

\section{The Role of Personal Transformation}

One of the most rewarding things about teaching and academic careers is the continued opportunity for personal growth. Inclusive pedagogies invite and require metacognitive reflection and a conscious commitment to personal 
transformation from engaged faculty. Inclusive pedagogies involve a journey with challenges, resistance, pushback, reflection, correction, and response.

An entire classroom does this work as a community, and faculty engage with this work individually. Some of the skillsets we have already discussed develop over time, often with the help of others. For example, how does a faculty member learn to normalize mistakes in front of students, taking risks to be vulnerable in that way? Or what kinds of learning are needed to become anti-racist, anti-sexist, anti-ableist, or to learn to implement inclusive pedagogies effectively? And, in the event that any of these moves should produce resistance from students, peers, or administrators, how are these best addressed and turned into transformative learning opportunities for them? When one or more of your innovations does not "fit" well with presumed norms for teaching evaluations, expected common tests, or the like, how does one navigate this?
Thankfully, these transformations do not need to - and indeed should not - happen all at once. It is enough to start with one classroom tweak, or to attend one workshop, or read one book or article, and build from there. Table 2 provides a list of helpful resources that can be places to start with some of the personal work - and there are likely additional resources available locally on your campus.

\section{CONCLUSION}

As $C E E$ authors consider how DEI can be aligned with scholarly aspects of the work published in the journal, they should examine the sociocultural context in which teaching and research occur. The learner experience is shaped through considerations at the individual learner level, in the classroom context, through peer and instructor interaction, and in engi-

\section{TABLE 2}

Resources to support the educator and researcher to begin a personal DEI transformation process

1.ASEE CDEI Virtual Workshops: https://diversity.asee.org/deicommittee/category/resources/virtualworkshops/

Recorded workshops on a range of topics including culturally responsive teaching, universal design for learning, and more.

2. Tatum, BD (2007). Ch 2: Connecting the Dots: How Race in America's Classrooms Affects Achievement. Can We Talk About Race? And Other Conversations in an Era of School Resegregation. Beacon Press. Boston, MA.

An introduction to systems of inequity in education and an unpacking of research on intelligence.

\section{Darder, A, Baltodano, MP, and Torres, RD (2017). The Critical Pedagogy Reader, 3rd ed.} Routledge. New York, NY.

An overview of the broad family of critical pedagogies, covering feminist, decolonizing, anti-racist, queer pedagogies, and more.

\section{Freire, $P$ (2000) Ch 2: The "Banking" Concept of Education as an Instrument of Oppression.} Pedagogy of the Oppressed. Bloomsbury. New York, NY.

A classic reading elucidating power dynamics in traditional teaching and learning.

\section{Banks, I (1998) Resistance in two acts: Practical and ideological implications. Feminist Teacher,} 12(1): 29-39.

A practical reflection on classroom, department, and institutional dynamics surrounding a woman of color teaching race in a predominantly White institution.

\section{T. Okun. White Supremacy Culture. https://www.whitesupremacyculture.info}

This website presents a way of understanding white supremacy culture, characteristics of white supremacy culture, and principles of racial equity useful in guiding racial justice practice. 
neering culture or society more broadly. We have presented numerous strategies that instructors can adopt to create a more equitable and inclusive environment for their students, and to have a positive impact on learning and identity formation. Efforts within chemical engineering education should not only consider the outcomes of research and teaching efforts but for whom and when they work. In this paper we have provided some specific examples of research-based strategies to integrate DEI into chemical engineering education, but there are many more ways to consider DEI. We encourage the $C E E$ community to think boldly about DEI and also to start somewhere. Change does not have to occur in a single term of teaching, but often happens over many years of intentional considerations.

\section{ACKNOWLEDGMENTS}

This material is based upon work supported by the National Science Foundation under IUSE/PFE:RED Grant No. 1632053, EEC 1539140 and 1929320, and CAREER 1554057 and 0448240. Any opinions, findings, and conclusions or recommendations expressed in this material are those of the authors and do not necessarily reflect the views of the National Science Foundation.

\section{REFERENCES}

1. National Academy of Sciences, National Academy of Engineering, and Institute of Medicine (2011) Expanding Underrepresented Minority Participation: America's Science and Technology Talent at the Crossroads. The National Academies Press. Washington, DC. https:// doi.org/10.17226/12984 accessed Jan. 29, 2021.

2. DeNavas-Walt C and Proctor BD (2014) Current Population Reports, P60-252, Income and Poverty in the United States: 2014. U.S. Census Bureau. Washington, D.C., https://www.census.gov/content/dam/Census/library/publications/2015/demo/p60-252.pdf accessed Feb. 2, 2021

3. National Science Foundation, National Center for Science and Engineering Statistics (2019) Women, minorities and persons with disabilities in science and engineering. https://ncses.nsf.gov/pubs/nsf21321/ accessed Mar. 1, 2021.

4. Lucena JC (2005) Defending the Nation: U.S. Policymaking to Create Scientists and Engineers from Sputnik to the 'War Against Terrorism'. University Press of America, Inc. Lanham, MD.

5. Slaton AE (2010) Race, Rigor and Selectivity in US Engineering: The History of An Occupational Color Line. Harvard University Press. Cambridge, MA.

6. Carter NM and Wagner HM (2011) Corporate performance and women's representation on boards (2004-2008). https://www.catalyst. org/wp-content/uploads/2019/01/the bottom line corporate performance and womens representation on boards 2004-2008.pdf accessed Apr. 4, 2021.

7. Devillard S, Graven W, Lawson E, Paradise R, and Sancier-Sultan S (2012) Women Matter: Making the Breakthrough. McKinsey \& Company. https://www.mckinsey.com/ /media/McKinsey/Business\%20Functions/Organization/Our\%20Insights/Women\%20matter/ Women matter mar2012 english\%20(1).ashx accessed Apr. 4, 2021

8. Herring C (2009) Does diversity pay?: Race, gender, and the business case for diversity. American Sociological Review. 74(2):208-224. DOI: https://doi.org/10.1177/000312240907400203.
9. Gurin P (1999) The expert report of Patricia Gurin. Michigan Journal of Race and Law. 5. https://repository.law.umich.edu/mjrl/vol5/iss1/16 accessed Mar. 3, 2021.

10. Milem J (2003) Chapter 5: The Educational Benefits of Diversity: Evidence from Multiple Sectors. Compelling Interest: Examining the Evidence on Racial Dynamics in Higher Education. Chang MJ, Witt D, Jones J, Hakuta K, Eds. Stanford University Press. Stanford, CA.

11. Reason RD, Cox BE, Quaye BRL, and Terenzini PT (2010) Faculty and institutional factors that promote student encounters with difference in first-year courses. Review of Higher Education. 33(3):391-414. DOI: 10.1353/rhe.0.0137.

12. Smith H, Parr R, Woods R, Bauer B, and Abraham T (2010) Five years after graduation: Undergraduate cross-group friendships and multicultural curriculum predict current attitudes and activities. Journal of College Student Development. 51(4):385-402. DOI: 10.1353/csd.0.0141.

13. Riley DM, Slaton A, and Pawley A (2014) Chapter 17: Social Justice and Inclusion: Women and Minorities in Engineering. Cambridge Handbook of Engineering Education. Johri A, Olds BM, Eds. Cambridge University Press. New York.

14. Stuppard CM (2018) Diversity benchmarking report for underrepresented groups in engineering. https://ira.asee.org/diversity-benchmarkingreport-for-underrepresented-groups-in-engineering-and-engineeringtechnology/ accessed Mar. 3, 2021.

15. American Society for Engineering Education Engineering Data Management System. ASEE Institutional Data and Analytics. Washington, D.C.

16. National Science Board, National Science Foundation (2019) Science and engineering indicators 2020: Science and engineering labor force. https://ncses.nsf.gov/pubs/nsb20198/ accessed March 7, 2021.

17. Fouad NA, Chang W-H, Wan M, and Singh R (2017) Women's reasons for leaving the engineering field. Frontiers in Psychology. 8(875). DOI 10.3389/fpsyg.2017.00875.

18. Haring-Smith T (2012) Broadening our definition of diversity. Liberal Education 98(2) https://www.aacu.org/publications-research/periodicals/broadening-our-definition-diversity accessed November 1, 2017.

19. Collins PH (2001) Like one of the family: Race, ethnicity, and the paradox of US national identity. Ethnic and Racial Studies. 24(1):3-28. DOI: $10.1080 / 014198701750052479$.

20. American Psychological Association (2020) Ch.5: Bias-free Language Guidelines. Publication Manual of the American Psychological Association 7th Ed. American Psychological Association. Washington, DC.

21. AAC\&U. Making excellence inclusive. https://www.aacu.org/makingexcellence-inclusive accessed Nov. 1, 2017.

22. Olson S, Riordan, D. G. (2012) Engage to excel: Producing one million additional college graduates with degrees in science, technology, engineering and mathematics. Executive Office of the President, President's Council of Advisors on Science and Technology. Washington, DC. https://eric.ed.gov/?id=ED541511 accessed Jan. 20, 2021.

23. National Academy of Sciences, National Academy of Engineering, and Institute of Medicine (2016) Barriers and Opportunities for 2-year and 4-year STEM Degrees: Systemic Change to Support Students' Diverse Pathways. The National Academies Press. Washington, DC. DOI: https://doi.org/10.17226/21739.

24. ABET. Criteria for accrediting engineering programs, 2021-2022. https://www.abet.org/accreditation/accreditation-criteria/criteria-foraccrediting-engineering-programs-2019-2020/\#GC3 accessed Mar. 30, 2021.

25. AIChE. Equity, diversity and inclusion statement. https://www.aiche org/equity-diversity-inclusion/statement accessed March 30, 2021.

26. AIChE. Code of ethics. https://www.aiche.org/about/governance/policies/code-ethics accessed Mar. 30, 2021.

27. Freire $\mathrm{P}$ (2000) Pedagogy of the Oppressed, 30th Anniversary Edition. Bloomsbury. New York.

28. Stains M, Harshman J, Barker MK, Chasteen SV, Cole R, DeChennePeters SE, Eagan Jr. MK, Esson JM, Knight JK, Laski FA, LevisFitzgerald M, Lee CJ, Lo SM, McDonnell LM, McKay TA, Michelotti N, Musgrove A, Palmer MS, Plank KM, Rodela TM, Sanders ER, Schimpf NG, Schulte PM, Smith MK, Stetzer M, Valkenburgh BV, 
Vinson E, Weir LK, Wendel PJ, Wheeler LB, and Young AM (2018) Anatomy of STEM teaching in North American universities. Science. 359(6383):1468-1470. DOI: 10.1126/science.aap8892.

29. Rolston JS and Cox E (2015) Ch 13: Engineering for the Real World: Diversity, Innovation and Hands-on Learning. International Perspectives on Engineering Education: Engineering Education and Practice in Context. Volume 1. Christensen SH, Didier C, Jamison A, Meganck M, Mitcham C, Newberry B, Eds. Springer International Publishing. Cham, China.

30. Cech EA, Metz A, Smith JL, and deVries K (2017) Epistemological dominance and social inequality: Experiences of native american science, engineering, and health students. Science, Technology, \& Human Values. 42(5):743-774. DOI: 10.1177/0162243916687037.

31. Carrigan C and Bardini M (2021) Majorism: Neoliberalism in student culture. Anthropology \& Education Quarterly. 52(1):42-62. DOI: 10.1111/aeq.12361

32. Faulkner W (2000) Dualisms, hierarchies and gender in engineering. Social Studies of Science. 30(5):759-792. DOI: 10.1177/030631200030005005.

33. Cech EA and Waidzunas TJ (2011) Navigating the heteronormativity of engineering: The experiences of lesbian, gay, and bisexual students. Engineering Studies. 3(1):1-24. DOI: http://dx.doi.org/10.1080/1937 8629.2010.545065.

34. Cech EA and Sherick HM (2015) Ch 10: Depoliticization and the Structure of Engineering Education. International Perspectives on Engineering Education: Engineering Education and Practice in Context. Volume 1 Christensen SH, Didier C, Jamison A, Meganck M, Mitcham C, Newberry B, Eds. Springer International Publishing. Cham, CH.

35. Slaton AE (2015) Ch 8, Meritocracy, Technocracy, Democracy: Understandings of Racial and Gender Equity in American Engineering Education. International Perspectives on Engineering Education: Engineering Education and Practice in Context. Volume 1 Christensen SH, Didier C, Jamison A, Meganck M, Mitcham C, Newberry B, Eds. Springer International Publishing. Cham, $\mathrm{CH}$.

36. Villanueva I, Youmans K, Gelles L, and De Stefano M (2018) Hidden curriculum awareness: A comparison of engineering faculty, graduate students and undergraduates. World Education Engineering Forum Conference. https://par.nsf.gov/servlets/purl/10080823

37. Bejerano AR and Bartosh TM (2015) Learning masculinity: Unmasking the hidden curriculum in science, technology, engineering and mathematics courses. Journal of Women and Minorities in Science and Engineering 21(2):107-124. DOI: 10.1615/JWomenMinorScienEng.2015011359.

38. Milner HRI (2017) Confronting inequity / reimagining the null curriculum. Educational Leadership. 75(3):88-89. http://www.ascd.org/ publications/educational-leadership/nov17/vol75/num03/Reimaginingthe-Null-Curriculum.aspx

39. Carlone HB and Johnson A (2007) Understanding the science experiences of successful women of color: Science identity as an analytic lens. Journal of Research in Science Teaching. 44(8):1187-1218. DOI: 10.1002/tea.20237.

40. Foor CE, Walden SE, and Trytten DA (2007) "I wish that I belonged more in this whole engineering group:" Achieving individual diversity. Journal of Engineering Education. 96(2):103-115. DOI: 10.1002/ j.2168-9830.2007.tb00921.x.

41. Johnson A, Brown J, Carlone H, and Cuevas AK (2011) Authoring identity amidst the treacherous terrain of science: A multiracial feminist examination of the journeys of three women of color in science. Journal of Research in Science Teaching. 48(4):339-366. DOI: 10.1002/tea.20411

42. Malone KR and Barabino G (2009) Narrations of race in STEM research settings: Identity formation and its discontents. Science Education. 93(3):485-510. DOI: 10.1002/sce.20307.

43. Seymour E and Hewitt NM (1997) Talking about Leaving. Westview Press. Boulder, CO.

44. Eisenhart MA and Finkel E (1998) Women's Science: Learning and Succeeding from the Margins. University of Chicago Press. Chicago, IL.
45. Secules S (2019) Making the familiar strange: An ethnographic scholarship of integration contextualizing engineering educational culture as masculine and competitive. Engineering Studies. 11(3):196-216. DOI: 10.1080/19378629.2019.1663200.

46. Beasley MA and Fischer MJ (2012) Why they leave: The impact of stereotype threat on the attrition of women and minorities from science, math and engineering majors. Social Psychology of Education. 15(4):427-448. DOI: 10.1007/s11218-012-9185-3.

47. Steele CM, Spencer SJ, and Aronson J (2002) Contending with group image: The psychology of stereotype and social identity threat. $A d$ vances in Experimental Social Psychology. 34:379-440. DOI: 10.1016/ S0065-2601(02)80009-0.

48. Steele CM and Aronson J (1995) Stereotype threat and the intellectual test performance of african americans. Journal of Personality and Social Psychology. 69(5):797-811. DOI: 10.1037/0022-3514.69.5.797.

49. Jones BD, Ruff C, and Paretti MC (2013) The impact of engineering identification and stereotypes on undergraduate women's achievement and persistence in engineering. Social Psychology of Education. 16(3):471-493. DOI: 10.1007/s11218-013-9222-x.

50. Vygotsky LS (1980) Mind In Society: The Development of Higher Psychological Processes. Harvard University Press, Cambridge, MA.

51. Barker M. Practices for creating a culturally inclusive classroom. https:// intranet.secure.griffith.edu.au/ data/assets/pdf file/0015/34530/ Practices-for-Creating-a-Culturally-Inclusive-Classroom.pdf accessed Jan. 29, 2021.

52. Erikson EH (1956) The problem of ego identity. Journal of the American Psychoanalytic Association. 4(1):56-121. DOI: 10.1177/000306515600400104.

53. Burke PJ and Stets JE (2009) Identity Theory. Oxford University Press New York, NY.

54. Koretsky MD, Montfort D, Nolen SB, Bothwell M, Davis SC, and Sweeney JD (2018) Towards a stronger covalent bond: Pedagogical change for inclusivity and equity. Chemical Engineering Education. 52(2):117-127. https://journals.flvc.org/cee/article/view/105859 accessed Apr. 3, 2021.

55. Hall W, Schmader T, and Croft E (2015) Engineering exchanges: Daily social identity threat predicts burnout among female engineers. Social Psychology and Personality Science. 6(5):528-534. DOI: $10.1177 / 1948550615572637$

56. Steele CM (1997) How stereotypes shape intellectual identity and performance. American Psychologist. 52(6):613. DOI: 10.1037/0003066X.52.6.613.

57. Murphy MC, Steele CM, and Gross JJ (2007) Signaling threat: How situational cues affect women in math, science, and engineering settings. Psychological Science. 18(10):879-885. DOI: 10.1111/j.14679280.2007.01995.x.

58. Steele D and Cohn-Vargas B (2013) Identity Safe Classrooms: Places to Belong and Learn. Corwin. Thousand Oaks, CA

59. hooks b (1994) Teaching To Transgress: Education as the Practice of Freedom. Routledge. New York.

60. Gasiewski JA, Eagan MK, Garcia A, Hurtado S, and Chang MJ (2012) From gatekeeping to engagement: A multicontextual, mixed method study of student academic engagement in introductory STEM courses. Research in Higher Education. 53(2):229-261. DOI: 10.1007/s11162011-9247-y.

61. Godwin A and Potvin G (2017) Pushing and pulling sara: A case study of the contrasting influences of high school and university experiences on engineering agency, identity, and participation. Journal of Research in Science and Teaching. 54(4):439-462. DOI: 10.1002/tea.21372.

62. Manke MP(1997) Classroom Power Relations: Understanding Studentteacher Interaction. Erlbaum. Mahwah, NJ.

63. University of Utah, Center for Teaching and Learning Excellence. Sharing power in the classroom. https://utah.instructure.com/ courses/148446/pages/sharing-power-in-the-classroom accessed Apr. $1,2021$.

64. Stahlberg D, Braun F, Irmen L, and Sczesny S (2007) Section 1: Representation of the Sexes in Language. Social Communications. Klaus Fiedler. Psychology Press. New York, NY. 
65. Sczesny S, Formanowicz M, and Moser F (2016) Can gender-fair language reduce gender stereotyping and discrimination? Frontiers in Psychology. 7(25). DOI: 10.3389/fpsyg.2016.00025.

66. Godwin A, Potvin G, Hazari Z, and Lock R (2016) Identity, critical agency, and engineering: An affective model for predicting engineering as a career choice. Journal of Engineering Education. 105(2):312-340. DOI: $10.1002 /$ jee.20118.

67. Wright GB (2011) Student-centered learning in higher education. International Journal of Teaching and Learning in Higher Education. 23(1):92-97. https://www.isetl.org/ijtlhe/pdf/IJTLHE834.pdf

68. Hazari Z and Cass C (2018) Towards meaningful physics recognition: What does this recognition actually look like? The Physics Teacher. 56(7):442-446. DOI: 10.1119/1.5055325.

69. Rodriguez S, Cunningham K, and Jordan A (2019) Stem identity development for latinas: The role of self-and outside recognition. Journal of Hispanic Higher Education. 18(3):254-272. DOI: $10.1177 / 1538192717739958$.

70. Joshi A (2014) By whom and when is women's expertise recognized? The interactive effects of gender and education in science and engineering teams. Administrative Science Quarterly. 59(2):202-239. DOI: 10.1177/0001839214528331.

71. Beigpourian B, Ohland MO, and Ferguson DM (2019) The influence of percentage of female or international students on the psychological safety of team. FYEE Conference Proceedings. https://peer.asee. org/33732 accessed Jan. 29, 2021.

72. Ladson-Billings G (1995) Toward a theory of culturally relevant pedagogy. American Educational Research Journal. 32(3):465-491. DOI: 10.3102/00028312032003465

73. Reed AM, Tull RG, Delaine DA, Williams DN, and Sigamoney R (2016) Building global infrastructure for diversity and inclusion in engineering education. Proceedings ASEE International Forum. https:// peer.asee.org/27237. accessed Jan. 8, 2021.

74. Butterfield AE, McCormick A, and Farrell S (2018) Building LGBTQinclusive chemical engineering classrooms and departments. Chemical Engineering Education. 52(2):107-113. https://journals.flvc.org/cee/ article/view/105856 accessed Apr. 3, 2021.

75. Dasgupta $\mathrm{N}$ (2011) Ingroup experts and peers as social vaccines who inoculate the self-concept: The stereotype inoculation mode. Psychological Inquiry. 22(4):231-246. DOI: 10.1080/1047840X.2011.607313

76. Drury BJ, Siy JO, and Cheryan S (2011) When do female role models benefit women? The importance of differentiating recruitment from retention in STEM. Psychological Inquiry. 22(4):265-269. DOI: 10.1080/1047840X.2011.620935.

77. Cheryan S, Siy JO, Vichayapai M, Drury BJ, and Kim S (2011) Do female and male role models who embody STEM stereotypes hinder women's anticipated success in STEM. Social Psychological and Personality Science. 2(6):656-664. DOI: 10.1177/1948550611405218.

78. Riley D (2003) Employing liberative pedagogy in engineering education. Journal of Women and Minorities in Science and Engineering. 9(2). DOI: 10.1615/JWomenMinorScienEng.v9.i2.20.

79. Riley D, Claris L, Paul-Schultz N, and Ngambeki I (2006) Learning/ assessment: A tool for assessing liberative pedagogies in engineering education. Proceedings ASEE Annual Conference. DOI: 10.18260/1$2-154$.

80. Riley D and Claris L (2009) From persistence to resistance: Pedagogies of liberation for inclusive science and engineering. International Journal of Gender, Science and Technology. 1(1):36-60. http://genderandset.open.ac.uk/index.php/genderandset/article/view/25/28 accessed Jan. 29, 2021.

81. Riley D (2011) Engineering Thermodynamics and 21St Century Energy Problems: A Textbook Companion for Student Engagement. Morgan and Claypool. San Rafael, CA.

82. Mejia JA and de Paula MN (2019) "ingeniero como vos": An analysis of the mby'a-guaran'1 practices associated with engineering design. Proceedings ASEE Annual Conference. DOI: 10.18260/1-2--31921.

83. Sheppard S, Macatangay K, Colby A, Sullivan WM, and Shchulman LS (2009) Educating Engineers Designing for the Future of the Field. Josey-Bass. San Francisco.

Vol. 55, No. 4, Fall 2021
84. Svihla V, Datye AK, Gomez JR, Law V, and Bowers S (2016) Mapping assets of diverse groups for chemical engineering design problem framing ability. American Society for Engineering Education Annual Conference Proceedings. DOI: 10.18260/p.25675.

85. Gomez J and Svihla V (2018) Rurality as an asset for inclusive teaching in chemical engineering. Chemical Engineering Education. 52(2):99106. https://journals.flvc.org/cee/article/view/105855

86. Smith JM and Lucena JC (2016) Invisible innovators: How lowincome, first-generation students use their funds of knowledge to belong in engineering. Engineering Studies. 8(1):1-26. DOI: 10.1080/19378629.2016.1155593.

87. Flatt AK (2013) A suffering generation: Six factors contributing to the mental health crisis in north american higher education. College Quarterly.16(1). http://collegequarterly.ca/2013-vol16-num01-winter/ flatt.html

88. Godfrey E and Parker L (2010) Mapping the cultural landscape in engineering education. Journal of Engineering Education. 99(1):5-22. DOI: $10.1002 / \mathrm{j} .2168-9830.2010 . t b 01038 . x$.

89. Stevens R, Amos D, Jocuns A, and Garrison L (2007) Engineering as lifestyle and a meritocracy of difficulty: Two pervasive beliefs among engineering students and their possible effects. Proceedings American Society for Engineering Education Annual Conference. DOI: $10.18260 / 1-2--2791$.

90. Cross KJ and Jensen KJ (2018) Work in progress: Understanding student perceptions of stress as part of engineering culture. American Society for Engineering Education Annual Conference Proceedings. DOI: $10.18260 / 1-2--31312$.

91. Clements H, Benedict B, Godwin A, Rohde J, and Chen S (2020) "Adversary or ally": Undergraduate engineering students' perceptions of faculty. Proceedings American Society for Engineering Education Annual Conference. DOI: 10.18260/1-2--33966.

92. Christe BL (2013) The importance of faculty-student connections in stem disciplines. Journal of STEM Education: Innovations and Research. 14(3):22-26. https://eric.ed.gov/?id=EJ1017074

93. Waterman AS, Schwartz SJ, and Conti R (2006) The implications of two conceptions of happiness (hedonic enjoyment and eudaimonia) for the understanding of intrinsic motivation. Journal of Happiness Studies. 9:41-79. DOI: 10.1007/s10902-006-9020-7.

94. Rieken B, Shapiro S, Gilmartin S, and Sheppard SD (2019) How mindfulness can help engineers solve problems. Harvard Business Review. https://hbr.org/2019/01/how-mindfulness-can-help-engineerssolve-problems accessed January 29, 2021.

95. Ge JS, Berger EJ, Major JC, and Froiland JM (2019) Teaching undergraduate engineering students gratitude, meaning, and mindfulness, American Society for Engineering Education Annual Conference Proceedings. DOI: 10.18260/1-2--33358.

96. Rieken B, Schar M, and Sheppard S (2016) Trait mindfulness in an engineering classroom: An exploration of the relationship between mindfulness, academic skills, and professional skills, Proceedings IEEE Frontiers in Education Conference. DOI: https://doi.org/10.1109/ FIE.2016.7757464.

97. Chang TH (2019) Dare to care? An exploration of student-teacher caring relationships Doctoral Dissertations. University of New Hampshire, Durham, NH. https://scholars.unh.edu/dissertation/2440

98. Chhoun V and Wallace TL (2014) Creating connectedness through being known: Fulfilling the need to belong in us high schools. Youth and Society. 46(3):379-401. DOI: 10.1177/0044118X11436188.

99. Thompson A (1998) Not the color purple: Black feminist lessons for educational caring. Harvard Educational Review . 68(4):522-555. DOI: 10.17763/haer.68.4.nm436v83214n5016.

100. Valenzuela A (1999) Subtractive Schooling: U.S.-Mexican Youth and the Politics of Caring. State University of New York Press. Albany, NY.

101. Carberry AR and Baker DR (2018) The Impact of Culture on Engineering and Engineering Education. Springer Nature. Cham, $\mathrm{CH}$.

102. Guarino CM and Borden VM (2017) Faculty service loads and gender: Are women taking care of the academic family? Research in Higher Education. 58(6):672-694. DOI: 10.1007/s11162-017-9454-2. 
103. Cornielle M, Lee A, Allen S, Cannady J, and Guess A (2019) Barriers to the advancement of women of color faculty in STEM. Equity, Diversity and Inclusion: An International Journal. DOI: 10.1108/ EDI-09-2017-0199.

104. Rosenthal R (2002) Covert communication in classrooms, clinics, courtrooms, and cublcles. American Psychologist. 57(11). DOI: 10.1037/0003-066X.57.11.839.

105. Atadero RA, Paguyo CH, Rambo-Hernandez KE, and Henderson HL (2018) Building inclusive engineering identities: Implications for changing engineering culture. European Journal of Engineering Education. 43(3):378-398. DOI: 10.1080/03043797.2017.1396287.

106. League A-D. Let's get it right: Using correct pronouns and names. https://www.adl.org/education/resources/tools-and-strategies/letsget-it-right-using-correct-pronouns-and-names accessed Mar. 3, 2021.

107. Zane S. Supporting transgender students in the classroom. https://www.facultyfocus.com/articles/effective-classroommanagement/supporting-transgender-students-classroom/?utm campaign=shareaholic\&utm medium =facebook\&utm source=socialnetwork accessed Mar. 30, 2021.

108. Clemson University. Diversity and inclusion syllabus statements. https://www.clemson.edu/otei/documents/Teaching\%20Review\%20 Resources/Diversity InclusionSyllabiSamples.pdf accessed Mar. 3, 2021.

109. McCroskey JC and McVetta RW (1978) Classroom seating arrangements: Instructional communication theory versus student preferences. Communication education. Communication Education. 27(2):99-111. DOI: $10.1080 / 03634527809378281$.

110. Mamboleo G, Meyer L, Georgieva Z, Curtis R, Dong S, and Stender LM (2015) Students with disabilities' self-report on perceptions toward disclosing disability and faculty's willingness to provide accommodations. Rehabil Couns Educ J. 8(2):8-19. https://pubmed.ncbi.nlm.nih. gov/31008459 accessed Feb. 8, 2021.

111. Kranke D, Jackson SE, Taylor DA, Anderson-Fye E, and Floersch J (2013) College student disclosure of non-apparent disabilities to receive classroom accommodations. Journal of Postsecondary Education and Disability. 26(1):33-51.https://files.eric.ed.gov/fulltext/EJ1026808.pdf

112. CAST. Universal design for learning guidelines version 2.2. http:// udlguidelines.cast.org accessed Mar. 21, 2021.

113. The Center for Universal Design in Education. Universal design of instruction. https://www.washington.edu/doit/programs/center-universal-design-education/postsecondary/universal-design-instruction. accessed Aug. 9, 2021.

114. Knowles MS (1975) Self-directed Learning: A Guide for Learners and Teachers. Association Press. New York, NY.

115. Ambrose SA, Bridges MW, DiPietro M, Lovett MC, and Norman MK (2010) How Learning Works: Seven Research-based Principles for Smart Teaching. Jossey-Bass. New York, NY.

116. Dweck C (2006) Mindset: The New Psychology of Success. Random House. New York, NY.

117. Yeager DS, Hanselman P, Walton GM, Murray JS, Crosnoe R, Muller C, Tipton E, Schneider B, Hulleman CS, Hinojosa CP, Paunesku D, Romero C, Flint K, Roberts A, Trott J, Iachan R, Buontempo J, Yang SM, Carvalho CM, Hahn PR, Gopalan M, Mhatre P, Ferguson R, Duckworth AL, and Dweck CS (2019) A national experiment reveals where a growth mindset improves achievement. Nature. 573(7774):364-369. DOI: 10.1038/s41586-019-1466-y.

118. Canning EA, Muenks K, Green DJ, and Murphy MC (2019) STEMfaculty who believe ability is fixed have larger racial achievement gaps and inspire less student motivation in their classes. Science Advances. 5(2):eaau4734. DOI: 10.1126/sciadv.aau4734.

119. Capobianco BM and Yu JH (2014) Using the construct of care to frame engineering as a caring profession toward promoting young girls' participation. Journal of Women and Minorities in Science and Engineering. 20(1):21-33. DOI: 10.1615/JWomenMinorScienEng.2014006834.

120. Rulifson $G$ and Bielefeldt $A$ (2017) Motivations to leave engineering: Through a lens of social responsibility. Engineering Studies. 9(3):222248. DOI: $10.1080 / 19378629.2017 .1397159$.
121. McGee EO and Bentley L (2017) The equity ethic: Black and latinx college students reengineering their STEM careers toward justice. American Journal of Education. 124(1):1-36. DOI: 10.1086/693954.

122. Schiebinger L, Klinge I, Paik HY, Sánchez de Madariaga I, Schraudner M, and Stefanik M. Gendered innovations in science, health and medicine, engineering and environment. https://genderedinnovations. stanford.edu/ accessed Mar. 15, 2021.

123. Riley DM (2008) Engineering and social justice. Synthesis Lectures on Engineers, Technology and Society. 3(1):1-152. DOI: 10.2200/ s00117ed1v01y200805ets007.

124. Johnson K, Leydens JA, Moskal BM, Silva D, and Fantasky J (2015) Social justice in control systems engineering, Proceedings ASEE Annual Conference. DOI: 10.18260/p.24715.

125. Karwat D (2019) Ch. 10: Engineering for the People: Putting Peace, Social Justice and Environmental Protection at the Heart of all Engineering. Frontiers of Engineering: Reports on Leading-Edge Engineering from the 2018 Symposium. National Academy of Engineering. Washington, DC. https://www.nap.edu/read/25333/chapter/10 accessed Jan. 1, 2021.

126. Bovill C (2020) Co-creation in learning and teaching: The case for a whole-class approach in higher education. Higher Education. 79(6):1023-1037. DOI: 10.1007/s10734-019-00453-w.

127. Ribes-Giner G, Perello-Marín MR, and Díaz OP (2016) Co-creation impacts on student behavior, Proceedings Social and Behavioral Sciences. DOI: $10.1016 / j . s b s p r o .2016 .07 .011$.

128. Doyle E, Buckley P, and McCarthy B (2020) The impact of content cocreation on academic achievement. Assessment \& Evaluation in Higher Education. 46(3) 494-507. DOI: 10.1080/02602938.2020.1782832.

129. American Educational Research Association, American Psychological Association, and National Council on Measurement in Education (2014) Standards for Educational and Psychological Testing. American Educational Research Association. Washington, DC.

130. Douglas KA and Purzer Ş (2015) Validity: Meaning and relevancy in assessment for engineering education research. Journal of Engineering Education. 104(2):108-118. DOI: 10.1002/jee.20070.

131. Salehi S, Cotner S, Azarin SM, Carlson EE, Driessen M, Ferry VE, Harcombe W, McGaugh S, Wassenberg D, Yonas A, and Ballen CJ (2019) Gender performance gaps across different assessment methods and the underlying mechanisms: The case of incoming preparation and test anxiety, Proceedings Frontiers in Education. DOI: 10.3389/ feduc.2019.00107.

132. Major JC, Scheidt M, Godwin A, Berger EJ, and Chen J (2020) Effects of test anxiety on engineering students' STEM success, Proceedings American Society for Engineering Education. DOI: 10.18260/1-2-34511.

133. Inzlicht M, and Schmader T (2012) Stereotype Threat: Theory, Process, and Application. Oxford University Press. New York, NY, US.

134. Washington University in St. Louis. Reducing stereotype threat. https:// ctl.wustl.edu/resources/reducing-stereotype-threat/.

135. Brown University, The Harriet W. Sheridan Center for Teaching and Learning. Strategies and resources about stereotype threat. https://www. brown.edu/sheridan/teaching-learning-resources/inclusive-teaching/ stereotype-threat accessed Jan. 4, 2021.

136. Farrell S and Minerick AR (2018) The stealth of implicit bias in chemical engineering education, its threat to diversity, and what professors can do to promote an inclusive future. Chemical Engineering Education. 52(2):129-135. http://journals.fcla.edu/cee/article/view/105861 accessed Apr. 3, 2021.

137. Wiggins G (1990) The case for authentic assessment. Practical Assessment, Research and Evaluation. 2(2). DOI: 10.7275/ffb1-mm19.

138. Smith E and Reeves R (2020) Sat math scores mirror and maintain racial inequity. Brookings https://www.brookings.edu/blog/upfront/2020/12/01/sat-math-scores-mirror-and-maintain-racial-inequity/ accessed Jan. 20, 2021. $\square$ 